\title{
Sistem Informasi Jurnal Online Politeknik Negeri Balikpapan
}

\author{
Armin, Ali Abrar \\ Jurusan Teknik Elektronika \\ Politeknik Negeri Balikpapan \\ Jl. Soekarno Hatta Km.8 Balikpapan Tlp. (0542) 860895 Fax. 861107 \\ Email : ali.abrar@poltekba.ac.id
}

\begin{abstract}
Balikpapan State Polytechnic currently has a scientific journal that has been published on a regular basis, but so far it is still used in some print media have limited side to create and publish.

Along with the development of information technology today, we need a media that can help the print media is limited by the online system. The objective and target of this research are to design, build and test online scientific journal of state Polytechnic of Balikpapan. Selection of online media is used to be accessible anytime and anywhere.

With the online journal of information systems State Polytechnic of Balikpapan is to provide convenience in the management of information systems journals and the development of information technology in the field of online publishing.
\end{abstract}

Keywords: Information System, Online Journal.

\begin{abstract}
Abstrak
Politeknik Negeri Balikpapan saat ini sudah memiliki jurnal ilmiah yang sudah terbit secara berkala, namun sejauh ini masih menggunakan media cetak yang dalam beberapa sisi memiliki keterbatasan untuk membuat dan menerbitkannya.

Seiring dengan perkembangn teknologi informasi dewasa ini maka diperlukan suatu media yang dapat membantu keterbatasan media cetak yaitu dengan sistem online. Tujuan dan target penelitian ini adalah untuk merancang, membuat dan menguji jurnal ilmiah online Politeknik Negeri Balikpapan. Pemilihan media online digunakan agar dapat diakses kapan dan dimana saja.

Dengan adanya sistem informasi jurnal online Politeknik Negeri Balikpapan ini dapat memberikan kemudahan dalam pengelolaan sistem informasi jurnal dan pengembangan teknologi informatika dalam bidang penerbitan online
\end{abstract}

Kata Kunci: Sistem Informasi, Jurnal Online

\section{Pendahuluan}

Sesuai dengan surat yang dikeluarkan oleh Dikti Nomor: 152/E/T/2012 tentang publikasi karya ilmiah dimana jumlah karya ilmiah dari perguruan tinggi di Indonesia masih rendah, yaitu sepertujuh dibandingkan dengan negara Malaysia, maka diperlukan upaya untuk menjawab tantangan tersebut guna meningkatkan pembuatan dan penerbitan karya ilmiah dalam bentuk jurnal (Dikti:2012).

Pada umumnya jurnal yang ada dibuat dan diterbitkan dalam media cetak, meskipun memiliki kelebihan namun dalam beberapa hal terdapat kekurangan seperti terbatas ketersediaannya, proses mulai dari pengumpulan, pengeditan dan pencetakan yang membutuhkan waktu tenaga dan biaya yang tidak sedikit.

Untuk itulah maka diperlukan media alternatif yakni dengan menggunakan media online. Sebagaimana yang sudah di ketahui bahwa saat sekarang penggunaan fasilitas teknologi informasi seperti komputer desktop, laptop, tablet, smartphone serta internet sudah dan akan 
bertambah banyak termasuk di bidang pendidikan. Dengan adanya jurnal online dunia pendidikan (Dosen atau Mahasiswa) untuk menemukan informasi yang dinginkan secara lebih tepat dan cepat tanpa harus dibatasi dengan kendala keterbatasan ruang dan waktu sehingga pada akhirnya juga dapat ikut turut serta memajukan pendidikan di Indonesia di masa yang akan datang.

\section{Metoda Penelitian}

\section{Tempat dan Waktu Penelitian}

Penelitian ini direncanakan untuk dilakukan di komputer laptop dan server lokal jaringan Politeknik Negeri Balikpapan setelah itu baru di upload di server internet. Jangka waktu yang diperlukan untuk penelitian ini akan dilakukan selama waktu 3 Bulan..

\section{Tahap-tahap Penelitian}

Adapun waktu dan tahap-tahap penelitian yang akan dilakukan adalah sebagai berikut:

\section{Tahap Perancangan}

Penelitian proses perancangan melalui 6 tahap yaitu:
1) Analisis Kebutuhan Jurnal Online Poltekba;
2) Strategi Pengembangan Jurnal Online;
3) Instalasi Web Server;
4) Download file instalasi OJS;
5) Instalasi Sistem;
6) Konfigurasi

\section{Tahap Implementasi}

Penelitian pengisian konten melalui 4 tahap yaitu
1) Input/Entri jurnal data,
2) Backup data,
3) Upgrade dan
4) Partisipasi.

\section{Tahap Pengujian Sistem}

Penelitian penerbitan jurnal online di internet yang meliputi:

1) Hosting website

2) Upload sistem dan data jurnal diharapkan dapat memudahkan akses bagi

3) Publikasi dan sosialisasi

Flowchart Penelitian

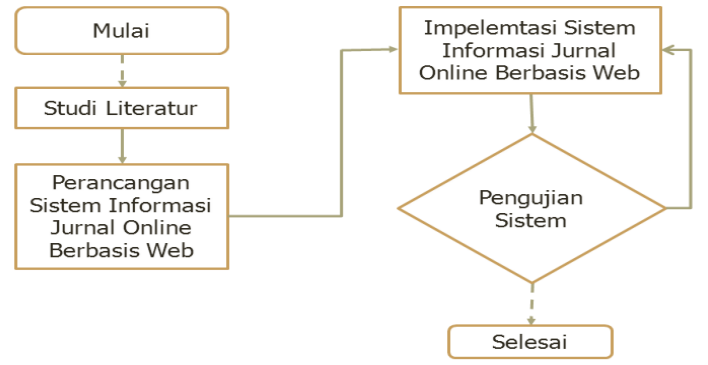

\section{Hasil dan Pembahasan}

\section{Proses Instalasi}

Proses instalasi dilakukan secara Offline (Localhost) dan online (Hosting di Internet).

Pada instalasi secara ofline Instalasi secara offline digunakan laptop dengan spesifikasi Hardware:

Prosesor: Intel® Core ${ }^{\mathrm{TM}}$ i3 CPU M 370 @ $2.40 \mathrm{GHz} \times 4$; Memori $1.8 \mathrm{GiB}$; Hardisk 49.6 GB dan Software: Sistem Operasi Ubuntu 12.04.1 LTS; Web server Apache/2.2.22, PHP/5.3.10-1, Mysq1 5.5.28

Dengan mengikuti panduan instlasi yang terdapat pada manual program hasil nya seperti pada gambar 2 :

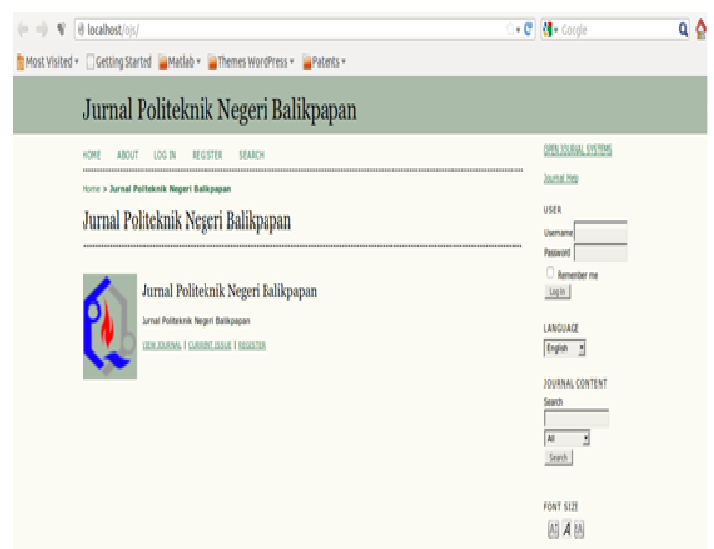

Gambar 2: Hasil Instalasi Sistem Offline

Setelah berhasil melakukan proses instalasi secara offline kemudian dilanjutkan dengan instalasi secara online (hosting di internet) menggunakan alamat http://poltekba.ac.id/. Sebelum melakukan 
proses instalasi terlebih dahulu dilakukan pembuatan database dan user account secara manual oleh administrator webhosting setelah baru proses instalasi dapat dilakukan. Ketika pertama kali melakukan proses penginstalan digunakan OJS versi terbaru yakni 2.3.8. Dengan melakukan langkah-langkah yang sama seperti pada instalasi localhost proses instalasi dapat berjalan dengan lancer

Persoalan yang pertama mucul adalah ternyata versi yang terbaru belum terdapat dukungan bahasa Indonesia sehingga setelah dilakukan penelusuran lebih lanjut diperoleh bahwa memang sampai saat laporan ini ditulis versi yang mendukung untuk pilihan bahasa Indonesia masih versi 2.3.6. Oleh karena itu maka terpaksa dilakukan downgrade ke versi yang lebih rendah.Persoalan berikutnya adalah untuk versi 2.3.6 setelah dilakukan percobaan dan mencari informasi yang ada ternyata tidak dapat dilakukan secara offline (localhost) sehingga proses instalasi langsung dilakukan secara online. Ketika proses dilakukan secara online sebagaimana langkah-langkah sebelumnya akhirnya dapat berjalan tanpa kendala.

\section{Proses Editorial}

OJS mengatur dari awal pembuatan jurnal kiriman sama dengan menjadi jurnal. Tahap yang harus dilalui dalam lima langkah. proses editorial, yang akan dikelola oleh satu atau lebih dari editor:

1. Submissions Queue(Kiriman Antrian): Item mulai di sini dan ditugaskan untuk sebuah editor.

2. Submission Review: Item mengalami review dan editorial keputusan.

3. Submission Edit: Item mengalami copyediting, tata letak, dan proofreading.

4. Scheduling Queue (Penjadwalan Antrian): Item ditugaskan untuk masalah dan volume.

5. Table Of Content Daftar Isi: Item memerintahkan untuk publikasi dan isu yang diterbitkan.

\section{Administrasi Sistem}

Administrasi sistem meliputi bagaimana memulai situs dengan login sebagai administrator selanjutnya melakukan pengaturan-pengaturan melalui menu-menu yang terdapat pada manajemen situs.

\section{Membuat dan Me-manage Jurnal}

Sebelum melakukan pengaturan jurnal terlebih dahulu dibuat jurnal melalui menu "host Jurnal" yang terdapat pada bagian administrasi situs.

Setelah jurnal dibuat kemudian baru dilakukan pengaturan-pengaturan yang meliputi:

1. Melakukan setup jurnal baru

2. Berkas penelusuran

3. Bagian Jurnal

4. Statistik Laporan

5. Import dan Ekspor data

\section{Melakukan Setup Jurnal BaruEditor}

Untuk melakukan setup jurnal baru dipilih menu pada bagian 'Halaman Manajemen '. kemudian pada bagian 'Setup' dan ikuti 5 langkah untuk membuat jurnal. Lengkapi informasi yang diperlukan, perlu dingat bahwa informasi masih dapat diengkapi kembali sebagai tambahan apabila informasi belum bisa dilengkapi pada saat ini.

Tampilan halaman setup jurnal baru di tunjukkan seperti pada gambar 3

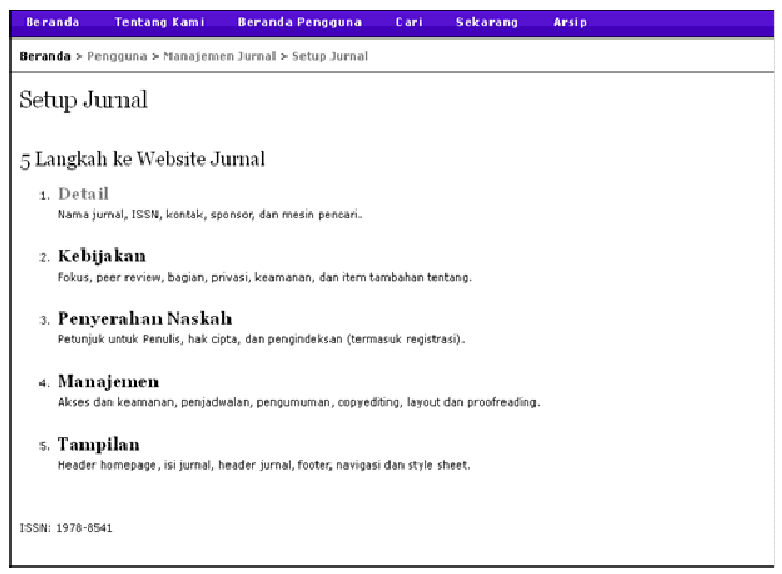

Editor editorial bertugas mengawasi seluruh proses penerbitan. Editor, bekerja sama dengan Manager Jurnal, yang biasanya membuat kebijakan dan prosedur 
untuk jurnal yang digunakan dalam menyiapkan jurnal yang akan di Setup. Dalam Proses Editorial, Redaksi memberikan kiriman ke Bagian

Editor dapat melihat Submission Review dan Edit Submission, pengawasan kemajuan tetap dilakukan oleh editor dan membantu apabila mengalami kesulitan. Editor juga dapat berperan dalam sebagai Editor proses, melihat kiriman diterima melalui copy editing, tata letak, dan proofreading. Editor juga menjadwal penghentian publikasi, mengatur Daftar Isi dan menerbitkan masalah, sebagai bagian dari Penerbitan Proses.

\section{Editor Bagian}

Bagian ini mengelola Review Editor dan Edit penyerahan naskah dari dalam bagian (misalnya, Artikel, Buku Review, dll), Orang yang bertanggung jawab telah ditetapkan. Jika Artikel itu sudah diterima untuk publikasi, Bagian yang Editor juga dapat mengawasi proses editing, yang dilakukan oleh Editor. Jurnal memiliki kebijakan tentang bagaimana tugas-tugas yang dibagi pada setiap anggota kerjanya.

\section{Reviewer}

Reviewer dipilih oleh Section Editor untuk meninjau sebuah kiriman(submission). Reviewers diminta untuk mengirimkan tinjauan ke jurnal situs web dan dapat mengupload lampiran untuk penggunaan Editor dan Author. Reviewer dapat nilai oleh Bagian Redaksi, tergantung pada kebijakan jurnal.

\section{Penulis}

Penulis dapat mendaftar dan mengirimkan item ke jurnal secara langsung ke jurnal melalui situs web. Author diminta untuk meng-upload item, serta menyediakan metadata atau informasi yang berkaitan pengindeksian dengan item, untuk meningkatkan kapasitas untuk pencarian online untuk jurnal ini.

Penulis yang juga dapat memberikan item dengan tambahan File dalam bentuk data set, instrumen penelitian, atau sumber teks yang akan memperkaya item, serta kontribusi untuk lebih terbuka dan kuat bentuk penelitian.

Penulis juga dapat melacak kiriman melalui proses editorial - serta partisipasi dalam copy editing dari proofreading pada kiriman yang diterima untuk publikasi. Penulis dapat login menggunakan username dan password yang diberikan.

Penulis juga dapat meminta pembayaran Author Submission dan/atau biaya Publikasi, dan mungkin juga opsional dapat membayar review Fast-Track, tergantung juga pada pengaturan kebijakan biaya jurnal tersebut.

\section{Pembaca}

Pembaca yang terdiri dari pelanggan yang dapat mengakses jurnal secara berlangganan dan pembaca yang memilih untuk mendaftar untuk membuka sekedar mengakses jurnal (apakah membuka akses atau setelah awal masa waktu setelah penerbitan konten jurnal).

Pembaca yang terdaftar menerima pemberitahuan untuk penerbitan masingmasing isu yang meliputi Daftar Isi dari jurnal. Tersedia juga menu 'Alat Baca' yang dimaksudkan untuk membantu pembaca yang ahli ataupun pemula untuk jurnal, membangun konteks, interpretasi, evaluasi dan memanfaatkan penelitian mereka. 'Alat Baca' telah dikembangkan untuk berbagai disiplin keilmuan.

\section{Panduan Singkat Upload Jurnal (mendigitlkan jurnal yang sudah ada/back issue).}

Jurnal yang sudah ada dalam bentuk cetakan akan diubah ke dalam format digital, dan akan dikelola selanjutnya dengan Open Journal System. Adapun beberapa langkah yang dapat dilakukan untuk mempercepat proses penyusunan jurnal diluar aturan ojs adalah sebagai berikut:

A. Scan Journal Cetak ke file digital 
Jurnal yang akan di digitalkan diubah dalam bentuk digital dengan bantuan scaner, kemudian disimpan dalam format *.pdf agar nanti pada saat upload dapat langsung di eksekusi.

Catatan untuk pembuatan file pdf:

1. Abstrak dan judul hendaknya tidak dikompress pada saat proses konvert ke *.pdf, hal ini dimaksudkan agar metadata file hasil (*.pdf) dapat dicopy dan dimasukkan dalam format xml.

2. Jika menginginkan pengkompressan untuk memperkecil file hasil(*.pdf), dapat dilakukan untuk file yang benarbenar akan di gunakan untuk upload, bukan untuk file metadata.

B. Menggunakan Quick Submit Plugin

Quick Submit Plugin terdapat pada halaman manajemen jurnal pada bagian halaman manajemen dan menu import/eksport data. Setelah login sebagai editor yang membuat edisi (Create Issue) dan mempublikasikannya. Lalu dengan Quick Submit Plugin artikel-artikel yang telah terbit dientri dan dikaitkan dengan edisi tertentu. Yang lama adalah proses scan artikel edisi awal, menyiapkan image halaman sampul untuk di web, mengatur ukuran file pdf artikel, dan memproses teks abstraknya. Hasil tampilan jurnal cetak yang diupload dengan Quick Submit Plugin adalah seperti gambar 3

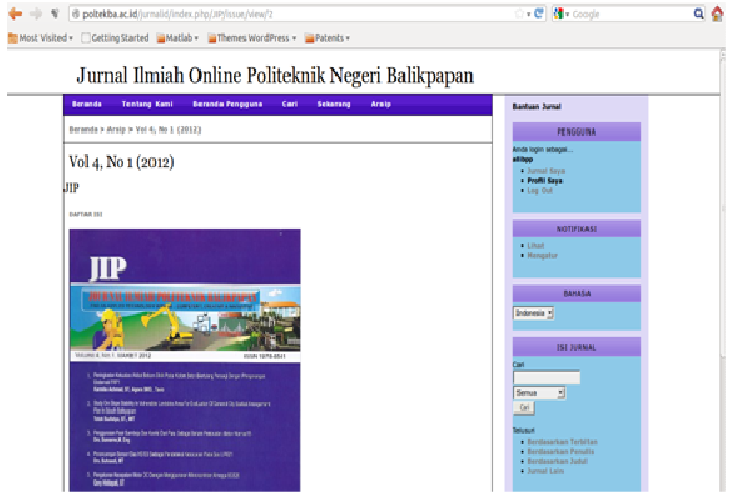

Gambar 3: Jurnal yang sudah di upload

\section{Kesimpulan}

Pemanfaatan sistem informasi jurnal online di Politeknik Negeri Balikpapan dapat menggunakan aplikasi konten manajemen sistem Open Journal System
(OJS) yang memang sudah di siapkan untuk keperluan jurnal online berbasis web sehingga dapat di gunakan khususnya bagi sivitas akademika Politeknik Negeri Balikpapan..

\section{Saran-Saran}

1. Perlu penambahan konten yang lebih lengkap, perubahan desain dan layout yang lebih baik.

2. Perlu seorang administrator atau komunitas yang konsern untuk mengembangkan sistem informasi jurnal online khusunya di Politeknik Negeri Balikpapan.

\section{Daftar Pustaka}

[1] Anonim (2012) e-journal, Menuju Jurnal Bereputasi Internasional, Presentasi LPPM Universitas Gadjah Mada

[2] Anonim (2012). Panduan singkat Open Journal System aseanjche. ugm.ac.id Pusat Pelayanan Teknologi Informasi dan Komunikasi andrew.getux.com

[3] Maia, Joao Prado (dkk)., (2006) Smarty PHP Template Programming and Applications.

[4] Kevin, Stranac,. (2010) Open Journal Systems: An Introduction to an Open Source Publishing Option

[5] Willinsky, John (dkk.). (2010 ) Open Journal Systems: An Example of Open Source Software for Journal Management and Publishing Published September 292010 Copyright (c) Simon Fraser University Library

[6] Willinsky, John (dkk.). (2010 ) Open Journal Systems: A Complete Guide to Online Publishing Published September 292010 Copyright (C) Simon Fraser University Library

[7] Zhao, Wenwu,. (2011) Starting an Academic Journal A Complete Guide for New Editors and Publishers. 